\title{
Malaria IN TRAVELLERS TO Gambia
}

\author{
Z Bisoffi (zeno.bisoffi@sacrocuore.it) ${ }^{1}$ \\ 1. Centre for Tropical Diseases, S. Cuore Hospital, Negrar, Verona province, Italy
}

Malaria incidence is reportedly declining steadily in many parts of the world, including in at least several African countries [1-3]. The incidence of imported malaria is also declining in a number of European countries [4-6]. However, incidence rates in travellers, both European tourists and the so called VFR (visiting friends and relatives) are difficult to estimate, due to problems with the numerator (many cases are not reported) and more importantly with the denominator, for which the information is generally lacking. An exception in the European Union is the United Kingdom (UK), where the International Passenger Survey provides a reliable denominator on the number of travellers to the different countries, duration of stay and reason for travel. Using this information and data on malaria notifications, British authors were recently able to show a steady decrease in the incidence rate of imported malaria from West Africa [6]. In their publication the authors comment that this trend is likely to mirror a true reduction in local malaria transmission, and argue that in some years guidelines on malaria prophylaxis might become less strict even in that part of the world, as it has already been proposed for other continents $[7,8]$. This time, however, has yet to come. The current issue of Eurosurveillance features two rapid communications about an unpredictable cluster of cases of falciparum malaria among European tourists returning from Gambia $[9,10]$. The first case reported from Denmark in November 2008, triggered a subsequent flow of notifications from other countries in Europe. Interestingly, many of these are northern European countries. Finland alone accounts for almost one quarter of the total cases. The Finnish cases are described and discussed in detail in the paper by $\mathrm{K}$ Valve et al. in this same issue [10]. The UK was the only country reporting more cases than Finland, which is not surprising, as many thousands of travellers from this country visit Gambia every year [6].

It is remarkable that as of 18 December, only three weeks after the first case was noted, we are able to discuss this cluster. Clearly, this would not have been possible with surveillance systems based on mandatory notifications. This emphasizes the usefulness of networks of clinicians such as TropNetEurop that can disseminate information among members very quickly; a characteristic feature that has helped to discover local epidemics of malaria and other tropical diseases in tourist resorts $[11,12]$ before they were picked up by local reporting systems.

To date it is not entirely clear if the cluster represents a true increase in local malaria transmission in Gambia, in contrast to a very recent report [3], or rather a coincidence that cheap (last minute or similar) tourist package holidays to Gambia are offered in several European countries. In connection with such travel, the risk of the disease is often clearly underestimated which results in large numbers of people travelling with no or with ineffective prophylaxis. The Finnish paper, however, indicates that the first hypothesis may be true. The authors state that there is only one travel agency organising package trips to Gambia, and that the number of travellers has not increased. However, no information is available on the use of prophylaxis in previous years [10]. Most patients in the cluster were tourists, while in general, in recent years, VFR accounted for the majority of malaria cases in many (albeit not all) European countries [5]. Gambian coastal and tourist area is comparatively small, and therefore a cluster in tourists might represent a local rather than a countrywide increase in transmission, although the latter cannot be ruled out. I assume that this aspect will soon be elucidated after more in depth evaluation of the situation by local authorities.

Apparently, the Finnish travel agency reacted in a very responsible way to the first notice of an increased malaria risk [10]. Unfortunately, the experience of experts in travel medicine shows that this is not always the case. Several patients in this cluster were counselled not to take any prophylaxis [9]. Lack of prophylaxis caused at least two avoidable malaria deaths and several severe cases requiring intensive care, one case is still suffering from neurological sequelae.

The outbreak emphasizes once more the need to maintain adequate awareness of malaria, even for tourist destinations where this risk is considered to be low or very low: I believe that European countries should consider possible legal implications in cases when travel agencies provide misleading messages.

Health professionals dealing with travel medicine should be aware of the fact that local malaria epidemiology may suddenly vary in countries, and unexpected occurrences should be immediately notified. Sources like TropNetEurop, Geo Sentinel, Promed, Eurosurveillance and others provide invaluable and timely information that is freely available and should be regularly consulted by all professionals giving travel advice.

\section{References}

1. Bhattarai A, Ali AS, Kachur SP, Mårtensson A, Abbas AK, Khatib R et al. Impact of artemisinin-based combination therapy and insecticide-treated nets on malaria burden in Zanzibar. PLOS Med. 2007;6;4(11):e309.

2. World Health Organization. Impact of long-lasting insecticidal nets (LLINs) and artemisinin-based combination therapies (ACTs) measured using surveillance data, in four African countries. Preliminary Report.Geneva: World Health Organization, 2008. Available from: http://www.who.int/malaria/docs/ ReportGFImpactMalaria.pdf. 
3. Ceesay SJ, Casals-Pascual C, Erskine J, Anya SE, Duah NO, Fulford AJ, et al. Changes in malaria indices between 1999 and 2007 in The Gambia: a retrospective analysis. Lancet. 2008;372(9649):1545-54.

4. Baas M, Wetsteyn J, van Gool T. Patterns of imported malaria at the Academic Medical Center, Amsterdam, The Netherlands. J Travel Med 2006;13(1):2-7

5. Mascarello M, Allegranzi B, Angheben A, Anselmi M, Concia E, Laganà S, et al. Imported malaria in adults and children: epidemiological and clinical characteristics of 380 consecutive cases observed in Verona, Italy. J Travel Med. 2008;15(4):229-36.

6. Behrens RH, Carroll B, Smith V, Alexander V. Declining incidence of malaria imported into the UK from West Africa. Malaria J. 2008;7(1):235.

7. Behrens RH, Bisoffi Z, Bjorkman A, Gascon J, Hatz C, Jelinek T, et al. Malaria prophylaxis policy for travellers from Europe to the Indian subcontinent. Malar J. 2006;5:7.

8. Behrens RH, Carroll B, Beran J, Bouchaud O, Hellgren U, Hatz C, et al. The low and declining risk of malaria in travellers to Latin America: is there still an indication for chemoprophylaxis? Malar J. 2007;6:114.

9. Jelinek T, Schade Larsen C, Siikamäki H, Myrvang B, Chiodini P, Gascon J, Visser L, Kapaun A, Just-Nübling G. European cluster of imported falciparum malaria from Gambia. Euro Surveill. 2008;13(51):pij=19077. Available from: http://www. eurosurveillance.org/ViewArticle. aspx?ArticleId=19077

10. Valve K, Ruotsalainen E, Kärki T, Pekkanen E, Siikamäki H. Cluster of imported malaria from Gambia in Finland - travellers do not listen to given advice. Euro Surveill. 2008;13(51):pii=19068. Available from: http://www.eurosurveillance. org/ViewArticle.aspx?ArticleId=19068

11. Jelinek T, Grobush M, Harms-Zwingenberger G, Kollaritsch H, Richter J, Zieger B. Falciparum malaria in European tourists to the Dominican Republic. Emerg Infect Dis. 2000;6(5):537-8.

12. Jelinek T, Bisoffi Z, Bonazzi L, van Thiel P, Bronner U, de Frey A, et al. Cluster of African trypanosomiasis in travelers to Tanzanian national parks. Emerg Infect Dis. 2002;8(6):634-5.

This article was published on 18 December 2008.

Citation style for this article: Bisoffi Z. Malaria in travellers to Gambia. Euro Surveill. 2008;13(51):pii=19078. Available online: http://www.eurosurveillance.org/ViewArticle. aspx?ArticleId $=19078$ 